\title{
Исследование методов пассивации и защиты каскадных солнечных элементов
}

\author{
(C) А.В. Малевская, Д.А. Малевский, П.В. Покровский, В.М. Андреев \\ Физико-технический институт им. А.Ф. Иоффее РАН, Санкт-Петербург, Россия \\ E-mail: amalevskaya@mail.ioffe.ru
}

Поступило в Редакцию 14 мая 2020 г.

В окончательной редакции 14 мая 2020г.

Принято к публикации 6 июля 2020 г.

\begin{abstract}
Проведены исследования методов пассивации и защиты $p-n$-переходов в местах их выхода на боковую поверхность меза-структуры и герметизации каскадных солнечных элементов на основе гетероструктуры $\mathrm{GaInP} / \mathrm{GaAs} / \mathrm{Ge}$. Выполнены исследования защитных покрытий на основе слоев нитрида кремния и силикона путем анализа темновых вольт-амперных характеристик солнечных элементов. Проведена оценка распределения электролюминесценции.
\end{abstract}

Ключевые слова: каскадный солнечный элемент, меза-структура, пассивирующие и защитные покрытия.

DOI: 10.21883/PJTF.2020.19.50043.18375

Каскадные солнечные элементы (КСЭ) широко используются в наземной и космической солнечной энергетике [1]. Рекордные значения КПД 47\% (АМ 1.5) получены для шестикаскадных солнечных элементов $\mathrm{A}_{3} \mathrm{~B}_{5}$ при 140-кратном концентрировании $(C)$ [2]. Агрессивное воздействие факторов окружающей среды (дождь, ветер, град, перепад температур) может приводить к деградации солнечных элементов в процессе их эксплуатации в составе солнечных батарей [3]. Для защиты КСЭ от воздействий факторов окружающей среды можно проводить пассивацию $p-n$-переходов в местах их выхода на боковую поверхность меза-структуры путем нанесения защитных покрытий, например, на основе пленок нитрида кремния, а также выполнять герметизацию фронтальной области элемента прозрачными диэлектрическими покрытиями на основе силикона. Силикон, используемый в концентраторной фотовольтаике, должен обеспечивать высокую прозрачность, устойчивость к термоциклированию, хорошую адгезию и механическую прочность под воздействием концентрированного солнечного излучения (при $C<1000)$ в течение всего срока эксплуатации КСЭ. Обзор силиконов, используемых для защиты солнечных элементов, приведен в [4]. В работах $[5,6]$ рассмотрены различные параметры деградации силиконовых герметиков под воздействием концентрированного солнечного излучения (при $\mathrm{C}<1000)$, термоциклирования при повышенных (до $\left.+240^{\circ} \mathrm{C}\right)$ и пониженных (до $-40^{\circ} \mathrm{C}$ ) температурах, а также при повышенной влажности. На основании этих испытаний сделаны выводы о возможности использования силиконовых герметиков для КСЭ. В настоящей работе проведены исследования методов пассивации и защиты $p-n$-переходов по боковой поверхности меза-структуры и герметизации КСЭ.

Постростовая технология изготовления КСЭ на основе гетероструктуры $\mathrm{GaInP} / \mathrm{GaAs} / \mathrm{Ge}$ включает этапы формирования омических контактов, антиотражающего покрытия и разделения гетероструктуры на чипы КСЭ. Операция разделения осуществляется путем травления слоев гетероструктуры и германиевой подложки [7]. Непосредственно после этапа формирования меза-структуры для защиты $p-n$-переходов по боковой поверхности мезы от воздействия факторов окружающей среды (пыли, влажности, перепадов температур) осуществляется пассивация $p-n$-переходов. В качестве материала пассивирующего диэлектрического слоя выбрана пленка нитрида кремния толщиной $100-150 \mathrm{~nm}$, выращенного методом плазмохимического осаждения при пониженном давлении с использованием высокочастотной плазмы. Использование нитрида кремния обусловлено его высокими барьерными характеристиками для диффузии молекул воды и кислорода, низкой скоростью окисления и высокой химической стойкостью.

Для увеличения степени защиты КСЭ проведена разработка технологии герметизации элементов после их монтажа на теплоотводящую плату с использованием силикона марки Elastosil@ S690 и защитного покровного стекла толщиной 130-170 $\mu \mathrm{m}$ (производитель Levenhuk, США). Разработанная технология герметизации КСЭ включает дозированное нанесение силикона, позиционирование покровного стекла строго над фоточувствительной областью и контролируемый прижим стекла (рис. $1, a, b)$. Размер покровного стекла задается в четком соответствии с площадью фоточувствительной области, токоотводящие проволоки остаются не закрытыми защитным стеклом, что обеспечивает улучшение теплоотвода от КСЭ за счет снижения площади материала с низкой теплопроводностью, примыкающего к элементу. При прижиме стекла происходит растекание силикона на область омического контакта и боковую разделительную мезу, что обеспечивает защиту контактов, включая места пайки токоотводящей золотой проволоки, 
$a$

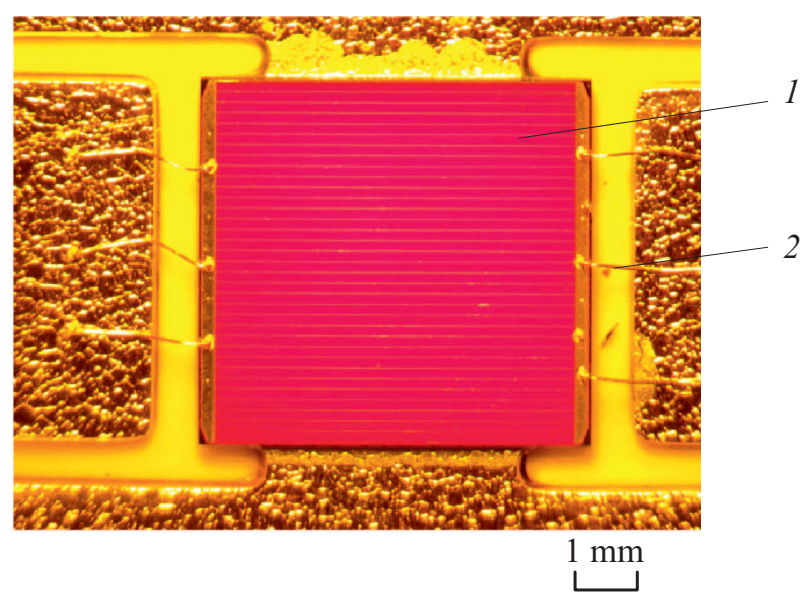

$b$

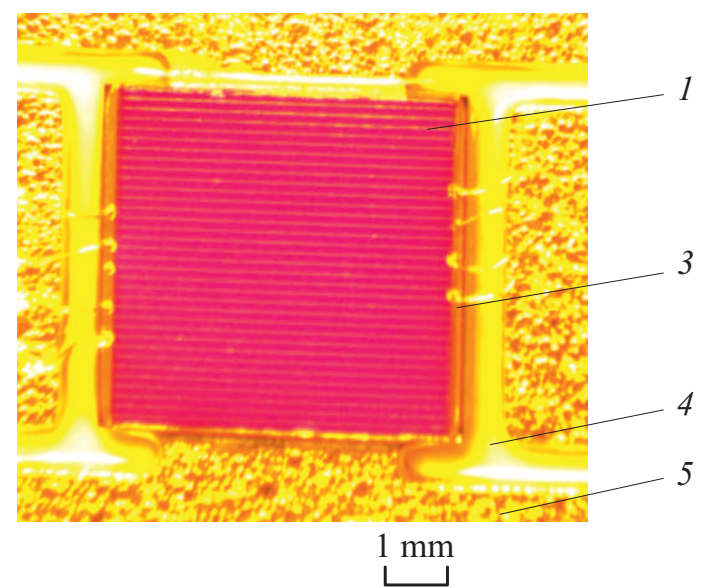

Рис. 1. Фотографии распределения электролюминесценции КСЭ на теплоотводящей плате. $1-$ КСЭ, $2-$ золотая проволока, 3 - защитное стекло, 4 - силикон, 5 - теплоотводящая плата. $a-$ до герметизации, $b-$ после герметизации КСЭ.

и герметизацию $p-n$-переходов в местах их выхода на боковую поверхность меза-структуры. Также при прижиме стекла происходит уменьшение толщины слоя силикона над фоточувствительной областью до $2-5 \mu \mathrm{m}$, что обеспечивает улучшение теплоотвода от элемента. КСЭ предназначен для работы при высоких степенях концентрирования солнечного излучения (более 500 крат) и плотности фототока более $10 \mathrm{~A} / \mathrm{cm}^{2}$, а снижение теплоотвода и нагрев элемента приводили бы к падению эффективности преобразования солнечного излучения в электроэнергию.

Стекло защищает солнечные элементы от частиц пыли и сопутствующих механических повреждений. Силикон обеспечивает надежную герметизацию КСЭ, защищает фронтальную область элементов, а также выполняет функцию адгезива для приклеивания защитного стекла. Стекло и силикон имеют близкие коэффициенты преломления, что позволяет исключить дополнительные потери на отражение излучения от границы стекло-силикон.

Для анализа качества герметизации проведены исследования распределения электролюминесценции по поверхности до и после герметизации образцов КСЭ. Равномерное свечение КСЭ по всей фронтальной поверхности свидетельствует об отсутствии дефектов и утечек тока как при монтаже КСЭ на плату (рис. 1, a), так и при проведении процесса герметизации КСЭ путем нанесения слоя силикона и механического прижима защитного стекла (рис. $1, b)$.

Для анализа качества и стойкости пассивирующего покрытия на основе нитрида кремния и процесса герметизации КСЭ силиконом были проведены испытания по термоциклированию элементов при повышенной влажности $85 \%$ и перепадах температур от -40 до $+85^{\circ} \mathrm{C}$. На темновых вольт-амперных характеристиках КСЭ без защитных покрытий наблюдается значительное увеличение токов утечки при значениях тока в диапазоне

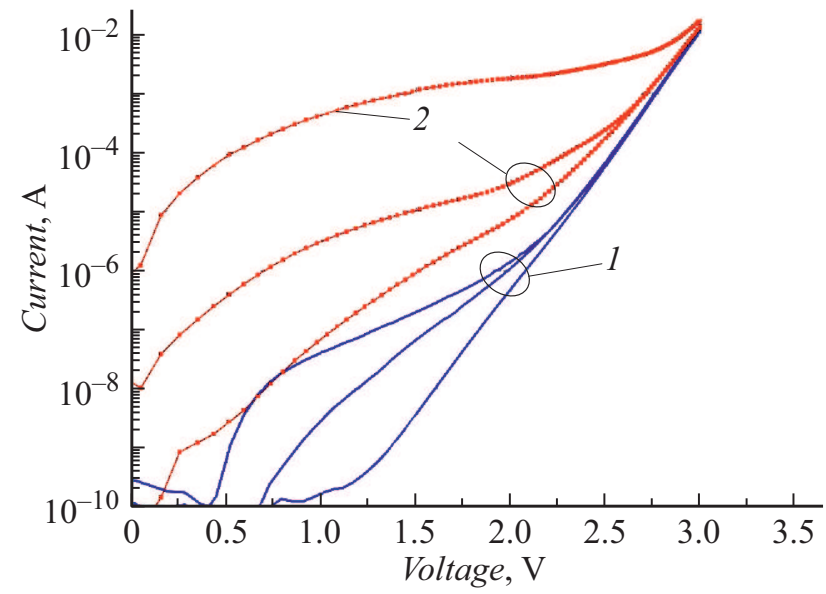

Рис. 2. Темновые вольт-амперные характеристики КСЭ без защитного покрытия до проведения процесса термоциклирования при повышенной влажности (1) и после термоциклирования (2).

$10^{-10}-10^{-2} \mathrm{~A}$ на большом количестве (более 25\%) исследованных образцов после проведения термоциклирования (рис. 2). На КСЭ с защитным покрытием $\mathrm{Si}_{3} \mathrm{~N}_{4}$ отмечается появление незначительных токов утечки (менее $10^{-4}$ A) на некоторых (менее $15 \%$ ) элементах после проведения термоциклирования (рис. 3). Возрастание тока утечки может происходить из-за небольшой толщины слоя $\mathrm{Si}_{3} \mathrm{~N}_{4}(100-150 \mathrm{~nm})$, что приводит к снижению стойкости при длительном термоциклировании. Однако в рабочем диапазоне токов (более $10^{-4} \mathrm{~A}$ ) КСЭ утечки не наблюдается, что свидетельствует о возможности использования защитного покрытия в технологии изготовления солнечных элементов.

На вольт-амперных характеристиках КСЭ после их герметизации силиконом практически не наблюдается изменения токов утечки после проведения испытания по 


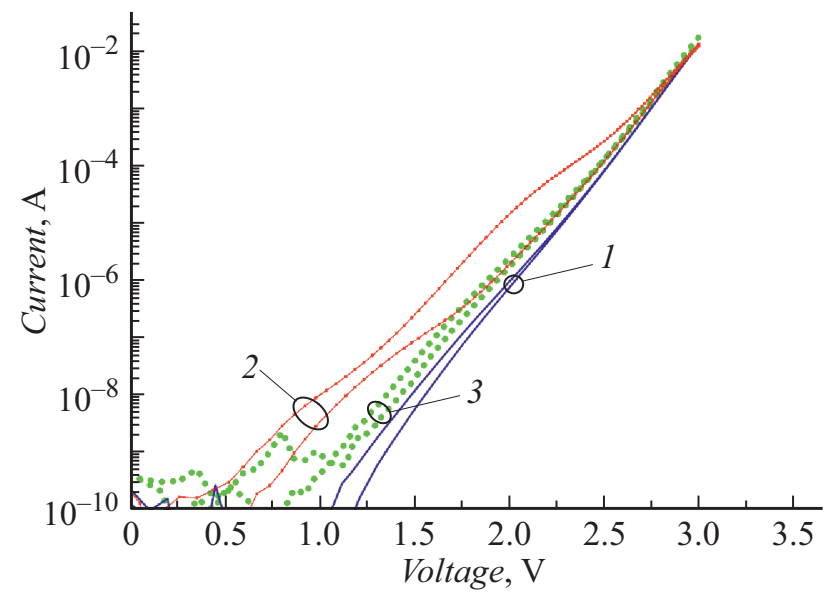

Рис. 3. Темновые вольт-амперные характеристики КСЭ до проведения процесса термоциклирования при повышенной влажности (1), после термоциклирования КСЭ с покрытием $\mathrm{Si}_{3} \mathrm{~N}_{4}(2)$ и с герметизацией силиконом (3).

термоциклированию, что указывает на высокое качество и стойкость силиконового покрытия к воздействию факторов окружающей среды.

Проведена разработка технологии защиты КСЭ пассивацией $p-n$-переходов путем плазмохимического осаждения пленок нитрида кремния. Разработана технология герметизации КСЭ путем нанесения слоя силикона и защитного покровного стекла. Результаты испытаний на стойкость покрытий показали отсутствие деградации КСЭ в рабочем диапазоне токов (более $10^{-4} \mathrm{~A}$ ) при повышенной влажности и значительных перепадах температур.

\section{Финансирование работы}

Исследование выполнено за счет гранта Российского научного фонда (проект № 17-79-30035).

\section{Конфликт интересов}

Авторы заявляют, что у них нет конфликта интересов.

\section{Список литературы}

[1] Alferov Zh.I., Andreev V.M., Rumyantsev V.D. // Concentrator photovoltaics / Eds A. Luque, V. Andreev. Springer Ser. in Optical Sciences. 2007. V. 130. P. 25-50.

[2] Green M.A., Dunlop E.D., Levi D.H., Hohl-Ebinger J., Yoshita M., Ho-Baillie A.W.Y. // Prog. Photovol.: Res. Appl. 2019. V. 27. N 7. P. 565-575. DOI: $10.1002 /$ pip.3171

[3] Honnurvali M.Sh., Gupta N., Keng Goh, Umar T., Nazeema N. // Int. J. Sustainable Energy Development (IJSED). 2017/18. V. 6. N 2. P. 335-343.

DOI: $10.20533 /$ ijsed.2046.3707.2017.0043

[4] Velderrain M. // AIP Conf. Proc. 2011. V. 1407. N 1. P. $79-83$. DOI: $10.1063 / 1.3658299$
[5] Eltermann F., Roeder K., Wiesenfarth M., Wilde J., Bett A.W. // AIP Conf. Proc. 2012. V. 1447. N 1. P. 276-280. DOI: $10.1063 / 1.4753885$

[6] Wiesenfarth M., Dörsam T., Eltermann F., Hornung T., Siefer G., Steiner M., Riesen S., Neubauer M., Boos A., Wanka S., Gombert A., Bett A.W. // AIP Conf. Proc. 2015. V. 1679. N 1. P. 100007. DOI: $10.1063 / 1.4931554$

[7] Малевская А.В., Ильинская Н.Д., Андреев В.М. // Письма в ЖТФ. 2019. Т. 45. В. 24. С. 14-16. DOI: 10.21883/PJTF.2019.24.48795.17953 